GENERAL ARTICLE

\title{
Some reflections on the theme of science \& education for citizenship: an essay
}

\author{
R.O.B.Wijesekera \\ No. 16, Kirimandala Mawatha, Rajagiriya.
}

Submitted: 27 March 2007 ; Accepted: 20 April 2007

\section{Preamble}

In the life of a modern citizen Science is overriding and appears uncompromisingly dominant. Never has science been so powerful and influential in the decades since it became a social influence. The paradox however is that to the large majority of the poorer people of the world, and here we are talking of billions, science is still indeed a stranger. Its beneficial effects hardly touch their lives but the effects of its dangers, such as today's sophisticated international terrorism, sometimes torment them, and devastate their humble lifestyles. Thus, from a global standpoint, and from that of the poorer people of the world, the question begs itself: Why Science? To respond to this one must first comprehend: What is Science? Why do we have Science?

Even long before recorded time, man's symbiotic relationship with his natural environment and his inherent curiosity, and the need to use it for food and shelter was the initial driving force to investigate. Wonderment at the natural phenomena led to the enhancement of his knowledge base. It also was the beginning of philosophies regarding the nature of the world, the universe and beyond. Man has always been a seeker of knowledge. It appears to be one of his intrinsic characteristics. Observation, curiosity, deduction, and hypothesizing appear to be the in the very nature of humankind. They are the ingredients that in time gave rise to science.

The early excursions of Man into the nature of the environment and speculative thinking of the nature of the world and the universe resulted in the early religious philosophies. Such philosophical- theories covered concepts regarding the nature of the solar system, and the lunar system, and gave rise to subjects such as astrology, and astronomy (later to be hijacked by science).
The same exploratory spirit led to the discovery of oceans and continents. And, the "primitive sciences", related to winds and waves, began to spell, power, prestige, and economic influence in the world. All this time the immediate environment too received man's attention, for it was the flora and the fauna that provided man with his food, clothing, and shelter, and even his medicines. It was this exploration of the environment that gave rise to the birth of Science, and scientific knowledge, and early agriculture. Eventually, the scientific method for the acquisition of knowledge came into play. The corpus of knowledge that we now call Science was built up this way. The scientific method went beyond observation and hypothesizing. It brought in the phenomenon of experimentation. Observation was followed by experimental observation, building theories, verification of these theories by further designing of experiments, compiling laws of nature based on the results and evaluation, and all these operations followed in a systematic, "la ronde". It is this la ronde that is the scientific method, by which knowledge in science is acquired, collated and built upon over time ${ }^{1,2}$.

However, let it not be understood that this is the only way that knowledge can be acquired. The noted biologist Sir Peter Medawar, FRS, Nobel Laureate, in his delightful book entitled: Induction and Intuition in Scientific Thought, has this to say ${ }^{3}$

"Ask a scientist what he conceives the scientific method to be and he will adopt an expression that is at once solemn and shifty eyed; solemn-because he feels he ought to declare an opinion; shifty-eyed because he is wondering how to conceal the fact that he has no opinion to declare".

Thus, not all scientists are aware of the scientific method, although they may practise it. Philosophy, in 
contrast, remains as such, not being verifiable by the type of experimentation we know of in science. As a consequence, philosophy could reach out to beyond the practical limitations of science, but remains abstract and with lesser practical relationship to man and his environment. However, the compelling symbiosis between man and the environment remains to this day, and leads to the craving of more knowledge, if it were for need as well as for greed. This craving is the driving force of science and exploration itself-life being inevitably a series of explorations. Thus science and the build up of scientific knowledge brings with it, prospects for man's continued sustenance as a species. It also brings dangers about which we shall deal with later.

\section{Science for whom, and for what?}

Some further questions emerge which demand responses: Why does mankind want Science? For what is Science? For whom is Science?

Let us now consider these.

Today Science is indeed part of the modern world's culture $^{3,4}$. Its real beginnings as modern science commenced after the Industrial Revolution in Europe, with the introduction of Newtonian Physics, and Robert Boyle's Laws in Chemistry. The founding of bodies, like the Royal Society in England and the Academie Royale des Sciences, in France, was also the beginning of organized science in Europe with these new institutions gaining the patronage of rulers like Charles the first, and Louis IV. Physics and Chemistry led the way to modern Biology with the Theories of Evolution of Charles Darwin ${ }^{1,4}$.

The discoveriess of the twentieth century have had the greatest impact on mankind. Researches on Natural Resources, both terrestrial and marine have led to a vast repertoire of knowledge for use by man for his benefit. The revolution in therapeutic agents came with the study of plant natural products which primitive man had been using and by studing the chemical structures of the molecules within them, man was able to make his own, for designed purposes. Synthetic polymers have revolutionized modern life, with materials that enable everything from computers to women's clothes, and now to nanotechnology. Studies of the winds and waves with man-made machines, ocean-draft, aircraft and satellites have enabled prediction of the weather to a nicety. Travel, transportation, and communications have changed, and are vastly different to what they were in the time of our own country's independence only half a century ago. Science and the science related technologies have moved the living style of citizens to a realm from where we cannot now recede. How many people, even some in remote areas of the globe, can now do without computers, cell phones, television, even i-pods and modern conveniences and transport?

Science is the agent of all this and we the citizens of the world cannot do without science. Besides, science is clearly now the factor that determines economic power and thus the level of life of all citizens ${ }^{4,5}$. If there is a vast difference between the rich nations and the poor, it parallels the respective capabilities in science and technology $y^{6}$. Yet there are three major characteristics, seemingly, the direct consequences of science that springs danger signals ${ }^{6,7}$.

Firstly, science as we have observed, and its benefits, have still to reach the poorest in the world. In a world of increasing prosperity and plentiful food supplies, about 840 million citizens still suffer from hunger and malnutrition. Of these, 799 million according to the Food and Agriculture Organization (FAO), live in developing countries where there is relatively little evidence of the beneficial effects of science. Although electricity and other forms of modern energy types operate in the affluent areas, their benefits have yet to reach a larger part of the world's citizens ${ }^{6,7}$.

The story is the same as regards water, health care, and social comforts ${ }^{8}$. Only, about $15 \%$ of the world 's population enjoys the bulk of $85 \%$ of the benefits of modern comforts.

Science has somehow or other, even accentuated the economic divide between the citizens of the rich countries and the poorest. Economic prosperity is now proportionate to the level of scientific capability.

Secondly, science has made awesome, the power of organized crime. The poorer countries as well the rich are both constantly embattled with this danger. Terrorism is indeed a global issue, but the danger is the fact that there is a political dichotomy in combating it. The impact of terrorism on the poorest sector received little attention, as the richer countries wade in to secure themselves. Recent examples of man-caused tragedies amply exemplify this.

Thirdly, science has given the world several selfdestructive handles which could be used with such horrendous destructive power, namely the potential of nuclear power, of genome related biotechnology and stem cell research. In this category, one may also place the potential of developments in contraceptive technology and the impact of their misuses. Hence in this aspect of danger, there is naught for our comfort. The science-political interface is responsible and this argues 
for the importance of future science education: an education directed towards citizenship and leadership in all spheres.

\section{Science education- a challenge and a dilemma}

Recent events have shown that, on the crucial issue of education for citizenship, science education must be linked to a moral and ethical foundation, which can be seen as legitimate by ordinary citizens. It must also be accepted as being responsive to their needs and interests. How science is taught in universities and particularly in schools is also vital to a public understanding of science.

Indeed the questions beg themselves: Who teaches? Teaches What? Teaches whom? If a ten year old asks questions about the universe, the climate, evolution, materials and minerals, plants and animals, the teacher should be equipped to reach for the information and deliver it to the student within his or her framework of comprehension. This means that curricula, teacher training, and teacher mechanisms, media and materials should be attuned to the new generation, who have been nurtured in a scientifically fashioned milieu. In addition can we install in the minimum university curriculum, the concept of scientists who are concerned genuinely for truth and clarification, if only for the rewarding experience of finding order and beauty in a chaotic jumble of natural events? May I quote ${ }^{9}$ the words of eminent American Physicist, Professor I.I. Rabi: "It is my belief that teaching science well in schools and universities is to enable students to learn what science is. It is to enable them to catch a glimpse of the heritage of man's experience and his symbiotic relationship with his environment. It is to understand man's experience in the context of the vast changes that surround us, born of new revelations enabled by the same technologies that appear awesomely foreboding”

The teaching of science therefore assumes a particularly crucial perspective ${ }^{10}$. How science is taught is vital to promoting a public understanding of science, which had consequences in the understanding of scientific matters by those entrusted with governance at all levels. I believe that students can best learn science by indulging in scientific inquiry themselves. They would find it appealing if the science they are learning is meaningfully connected to their own lives. It becomes then a memorable experience and not something to be memorized. Universities and schools should integrate scientific exploration with other disciplines for example, history, geography, languages, art and literature ${ }^{11,12}$. And as leading edge research releases new facts and concepts, the older untenable ones should be jettisoned. In this way, students will be responsive to new insights and knowledge.
What then are the main elements in the teaching of science? Firstly, there is the need to impart knowledge of and build a concept of what science is. This means that students should understand:

a) The heritage of scientific experience.

b) What sort of people made science?

c) How they did it and what they did.

d) The social implication of the technologies generated by science.

To do this, there must be people who are able to bridge the abysmal gap between cultures that are nurtured via science, with those like ours that are encumbered by tradition. Rodney Nochols puts it thus ${ }^{13}$.

"...The paradoxical and unfortunate mix of the modern and the mystical is understandable in terms of public trust of the scientific community. Debates on the environment, energy, and defence, engage apparent experts on every side of the issues. Hotly contested cases in court proceedings and legislative hearings may make it seem that scientific evidence is less reliable, less certain than was previously believed. Seeing this pattern students lose the natural curiosity about truthful explanations, become cynical about the motives of experts and wonder whether science and mathematics are worth the time and effort to master."

Add to this the third world phenomena of what has been referred to as 'quitting science', where students are attracted away from science due to other more compelling and remunerativee alternatives such as computing, management, marketing, accountancy etc ${ }^{7}$. Thus, the teaching of science must engage a whole new process. The process has to be installed and has to be forged with a continuous and harmonious association between those who teach science and non-science subjects. The goal must be one of delivering a composite literacy.

Those who actually do science know the manner in which we think about science itself. It is the manner in which we are trained to order the knowledge gathered by research, and try to understand the principles that could possibly give the results that are observed ${ }^{12-15}$. But one wonders if we do often enough look at the instrument that is science itself. What about the technologies that may be generated by the instrument? How could such be used or even misused? What are the best conditions for the scientific knowledge to be*employed to serve the needs we perceive? What are the factors that may be inimical for further growth? In what manner can we merge science into traditional methods to obtain the best of their wisdom? What factors would bring about the profitable 
use of science, and how may misuse be prevented? These are some of the reflections that scientists themselves should be trained to dwell on.

Therefore, unless we develop a critical understanding of how science works and functions in the human context, and most important would be the context of the vast majority that is the poor of the nations of the world, social problems in the use of science would undoubtedly arise. We can observe these in attempting to bring science to improve local industry which has a rural dimension.

One may be permitted a digression here to cite an example that was once encountered. In the 1970 's, the author and his research team were in the process of modernizing the traditional methods of distillation of essential oils in the rural areas of the southern coastline around Ambalangoda. One simple problem was that the oil distilled from cinnamon leaf was coloured green and was not acceptable to buyers. The colour was primarily due to the use of copper metal coils for the condensers. No amount of verbal scientific arguments, were acceptable to the distillers. They perceived the oils had to bear the colour of the leaves! Ultimately, a demonstration using glass apparatus to obtain colourless oil was the answer, coupled with another demonstration that the verdigris from the copper tainted the colourless oil green.

The scientific principles were easy to incorporate into the knowledge at village level when the critical facts were visibly demonstrated. It was easy then to incorporate further technological advances such as the use of multitubular condensers made of stainless steel, since the credibility of science has been established.

\section{Some emerging concepts}

E.O. Wilson, the eminent biologist, who delivered a keynote address at a Conference on 'The Unity of Knowledge' organized by the New York Academy of Sciences ${ }^{10,16}$ explained the concept he described in his book entitled 'Consilience - The Unity of Knowledge'. He asserted, that borderline disciplines such as cognitive neuroscience, human genetics, human socio-biology and biological anthropology would together provide us with a conception of human nature, and a unity of the natural and the human sciences. He dubbed this 'Consilience' which he subtitled as the Unity of Knowledge. Already the concepts of Wilson are bearing practical manifestations in the integration of the biological and the social sciences. However, what are the implications of such a concept in the teaching of science and liberal arts at the level of school and university? Thomas Tritton, ${ }^{16}$ a biochemist, believes that integrated knowledge and highly specialized research should co-exist, and that they would reinforce one another. He has however cautioned that "interdisciplinary" and "multi-disciplinary" could become covers for dilettantism and shallow level work.

Leon Ledermann, a mathematician, in considering science teaching and curricula has stated" ${ }^{13}$. "the teaching must employ the student's knowledge of biology, chemistry, physics, and mathematics, to provide, a coherence of understanding, which must also include history." He has proposed new curricula flowing seamlessly from physics and mathematics, through chemistry, biochemistry, and biological systems including the brain-mind connection. This he considers, if carried out in a proper manner, would contribute much to a wider knowledge of the science, and would enhance student as well as public interest in science.

The question that has received attention recently is whether all knowledge in intrinsically consilient. By that is meant, whether the broad branches of knowledge represented by the natural sciences, the social sciences and humanities are linked in some as yet strange manner. One concept is that they are connected by broad domains of less explored phenomena awaiting cooperative elucidation and understanding. Already several new sciences have emerged that appear to "bridge" the broad domains. They are such as: cognitive neuroscience or brain science, human genetics, human socio-biology and environmental biology. These flow from the side of the natural sciences. Then from the side of the social sciences the "domain-bridging" entities such as cognitive psychology and biological anthropology have emerged. In his major work E.O. Wilson ${ }^{10}$ dwells deeply on the significance of these bridging entities, of the knowledge domain, and believes that elucidation of them will eventually establish the concept of the unity of knowledge.

\section{History of Science}

This brings us to the importance of the history of science $^{4,13,17}$. The history of science depicts the story of the development of mankind's progressive ideas and their application towards the rise of technology through the ages. The ages of primitive technology were designated as the stone-age, the iron-age, the bronze-age etc. The ages that followed the industrial revolution too-which were science based-also bore technological tags such as the steam age, the electricity age, the electronic age, the nuclear age. Now we have come to the ages of information technology, biotechnology and nanotechnology.

It is important in the social context as well as in the understanding of science and technology to be aware of 
the historical developments in any field of relevance, and how several different disciplines of science have invariably contributed towards landmark events in science. Computers and the information revolution would not have been possible but for developments in chemistry, physics, and materials science. Developmentss in X-ray crystallography contributed massively in the elucidation of the structure of DNA, which has led to a billion dollar industry. The physical basis of modern disease diagnosis is another example of the success of the collaborative endeavours among different disciplines, which is also a massive industry today. Examples of such are now legion, which make the history of science such an absorbing subject of study for scientists, sociologists and historians. It represents the history of a major activity of humankind ${ }^{17}$.

\section{Knowledge and Wisdom}

In this context there is another aspect that should indeed be recognized. This is the difference between what we term as Knowledge and what is designated as Wisdom. Knowledge is the corpus of facts stored in the memory. The facts drawn via science are mostly related by certain recognized laws. Experience, curiosity and accumulated information are constituent components of our knowledge base. But wisdom is a quality of a different hue. Wisdom includes very much the experience of other people as well, their actions, information gathered by reading about them, observing the actions of others through history, literature, art, music, even archaeology and paleontology. This means a knowledge and experience and even understanding of the humanities. And in the service of civilization and in preparation for citizenship, it is wisdom that we have to strive for, in the teaching, learning, understanding and practice of science. For the acquisition of such wisdom, the teaching of science has to be re-tuned.

In the modern stage the formidable challenge lies in the fact that we are preparing students for a world that would be strange to teachers, stranger to students and all concerned and is change dependent. If one imagines what the world was at the time countries such as ours were granted independence, and compare it with what we experience today, we have some idea of the rate and extent of change. But scientific advances will ensure the rate of change in the future will be exponential in comparison. It will therefore be crucial that in educating students for future citizenship, they must develop the ability to function in strange, unpredictable, and even unforeseeable situations and this will be the norm. The strong framework of tradition that has kept the societies relatively stable, yet also, stationary, will no longer be relevant or functional.

\section{Impact of the Unity of Knowledge}

What will be the impact one wonders of the movement towards the unity of all knowledge, or of all knowledge being consilient, on the question of science and education for future citizenship? We should see this in a global setting, and indeed in the context of Sri Lanka? We may recall as stated heretofore, that science is a global activity and any indigenous scientific activity must have a link to global science. Initially we have also to accept that in Sti Lanka we are a pre-science culture. We have to initiate school learning in a manner that bestrides the vast gap between a modern scientific culture and our own prevalent traditional modes. Most times our traditional knowledge if properly harnessed would have considerable value. There is considerable merit in our systems of civil engineering, building, use of indigenous materials, our healthcare systems, our indigenous foods and food habits and methods of agriculture. Accordingly the possibility exists for the teaching of the core disciplines, supplemented by such chosen electives as the history of science, economic aspects, ayurvedic principles, agricultural practices, health and nutrition, the environment, the earth sciences, astronomy and astrology etc.

This calls for a paradigm change in school curricula and the curricula taught in the universities. It calls for teachers, teacher-trainers, university dons and other committed parties to work collegially together, to establish the knowledge coherence. Students will then be enabled to learn science as potent methodology and as a way of thinking and acquiring knowledge, and using it, not just as an accumulation of factual knowledge. This also calls for teachers to be afforded the opportunity, and obliged to constantly develop their professionalism and attendant skills, which will enable them to creatively effect the changes, that will lead to a new culture of learning led by the new concepts of a coherence of knowledge.

Hence, the school/university teaching must take a turn to revise the prevailing methods. Our greatest block is the methodology that has evolved around the 'tuition syndrome' prevalent in the Sri Lankan milieu. The syndrome has to be course-corrected. The goal must be to provide citizens not merely with scientific information, but with a scientific approach and methodology to bring to the solution of problems. Educational processes will have to be identified and put into operation, and these should result in the surfacing of such capabilities as adaptation and the ability to contend with new problems and new opportunities and give impetus to creativity and imagination. This means that in their learning process they must have practical experience of interdisciplinary as well as trans-disciplinary problems. Thus, in schools 
and the universities we will have to look across the entire range of the scientific knowledge base, and combine this with the wisdom of the humanities in some cohesive fashion. Hopefully, such methods will develop citizens with an ability to continually interact with a world in change. Obviously, the important component of such education must be the life-long learning habit, with modern information technology as the guide.

\section{Concluding observations}

In a world gone crazy in the pursuit of wealth and power, driven by science and technology, with demand and marketing as the accelerators, what matters is the manner in which scientists themselves cope with their inevitable involvement in public affairs. They should be concerned with values and goals, whether in research, in services or in policy formulation and execution. The moral-dimension and respect for the traditional knowledge,- albeit in a rational manner, for there is a wealth of wisdom in traditional knowledge and concepts,-must be paramount in the work of scientists on the local milieu.

On the other hand it must be borne in mind that scientists, that is the scientific community, belong to the Republic of Science, which is international ${ }^{14}$ and elitist by its very nature. Only scientists can participate in its deliberations and governance. But, as we observed earlier, science and the technology that derives from it, is today the very foundation of economic power and global wealth. And at the interface of science and politics the environment becomes treacherous. Politicians, those engaged in governance, and even the public, indulge in the debate with regard to applications of science and technology. The issues affect everyone. They may concern Agriculture, Food, Health, Water, Natural Resources, Energy, the Environment, Industry, and both man-made and natural disasters. They may also concern countering crime, and decisions to be made such as the suitability of genetically manipulated foods and the exercise of authority, over such other mattes that bear considerable scientific intervention.

At the same time, every citizen has a right to be heard whether it is within or without a framework of democracyat least a right to be heard. It is advantageous for the country to make certain that the majority of its citizens possess a basically rounded knowledge through appropriate education, particularly those in public and corporate governance. This makes it imperative that every citizen has some idea of the world we live in, dominantly intertwined by the culture pattern set by science and technology. Thus, an education about science is just as important as an education in science. An education based on the Unity of Knowledge ${ }^{16}$ may be a considerably good foundation.

The school curriculum that is exemplified by the international baccalaureate may be a modest beginning towards this end. There is common consent in the present science dominated world, that education in science and technology, whatever the intellectual and social dimensions are, is a key factor in the preparation of students for citizenship and the national workforce.

Accordingly, participation in global science is very much a national issue. A naive recipe would be a total withdrawal from global science: that would be suicidal. Hence the management of science and education in a country becomes crucial to its future citizenry, and to its very existence. This means the acquisition of a national capability in regard to pertinent discipline areas, the maintenance of adequate scientific personnel and institutions in research, in teaching and in other creative and productive activity, and, enabling them to interact continually with structural framework of society. The nation's future citizens have to be educated and conditioned, to address the formidable challenges that will face them.

Did that genius of a playwright William Shakespeare envisage it all when he wrote ${ }^{18}$. "Hereafter in a better world than this, I should desire more Love and Knowledge".

\section{References}

1. Van Doren C. (1991). A History of Knowledge: Past, Present and Future, Ballantine Books, New York.

2. Ciba Foundation Symposium 1(1973): Civilization and Science in Conflict of Collaboration? (Eds. Wolstenholme \& Connor) Ciba foundation, London 1993.

3. Medawar P.B. (1969). Induction and intuition in scientific thought. Jayne Lectures for 1968. American Philosophical Society, Philadelphia, USA.

4. Bernal J.D. (1969). Science in History. Harmondsworth: Penguin Books (Pelican Edition).

5. Zaragoza F.M. (1999). Science to what purpose? Editorial, UNESCO Courier, Paris.

6. Wijesekera R.O.B. (2001). Global Science and Third World Pigmies: Occasional Paper No 40, Central Bank of Sri Lanka, Colombo.

7. Wijesekera R.O.B. (2002). Pedestrians on the Highways of Global Science, COSTED occasional paper NO 7 , ICSU-COSTED, Chennai, India.

8. Shiva V. (2002). Water Wars:Privatisation, Pollution and Profit. South End Press, Cambridge, Massachusetts, USA.

9. Rabi L.L.(1970). Science: the Centre of Culture. World Publishing Co; New York.

10. Wilson E.0. (2001). How to unify knowledge. Annals of the NY Academy of Sciences 935:12-17. New York Academy of Sciences, New York. 
11. Pollack R. (2001). Some Practical suggestions for the teaching of Science in the liberal Arts Annals of the NY Academy of Sciences 935: 275-281. New York Academy of Sciences, New York.

12. Nichols R.W. (2001). Science in the Liberal Arts Curriculum Annals of the NYAcademy of Science 935:258260. New York Academy of Sciences, New York.

13. Ledermann L. (2001). Science Education as a Road to Consilient Curricula. 935:261-265. New York Academy of Sciences, New York.

14. Polyani M.(1962). The Republic of Science-Its Political and Economic theory. Minerva 1: 54-73. Cambridge University Press, UK.
15. Ziman J.(1968). Public Knowledge: The Social Dimension of Science. Cambridge University Press, UK.

16. Now York Academy of Sciences. (2001). unify knowledge: The Convergence of Natural and Human Science. (Eds. A.R. Damasio et al.) 935. New York Academy of Sciences, New York.

17. Hallemans A. \& Bunch B. (1988). The Timetables of Science: A Chronology of the Most Important People and Events in the History of Science. Simon and Schuster, New York.

18. Shakespeare W.(1969). As you like It. In: The Complete Works of Shakespeare. Ed. Alfred Harbage p.250. Penguin Books, Baltimore, USA. 